\title{
Correlation between Body mass index, Waist Hip ratio, blood sugar levels and blood pressure in apparently healthy adult Nigerians
}

\author{
Olumide A Abiodun ${ }^{1}$, Omodele A Jagun ${ }^{2}$, Oluwatosin O Olu-Abiodun ${ }^{3}$, John \\ O. Sotunsa ${ }^{4}$ \\ 1. Department of Community Medicine, Benjamin Carson (Snr) College of Medicine, Babcock University, Ilishan-Remo. Ogun State, \\ Nigeria. \\ 2. Department of Ophthalmology, Benjamin Carson (Snr) College of Medicine, Babcock University, Ilishan-Remo. Ogun State, Nigeria \\ The School of Nursing, Ijebu-Ode. Ogun State, Nigeria. \\ 4. Department of Obstetrics and Gynecology, Benjamin Carson (Snr) College of Medicine, Babcock University, Ilishan-Remo. Ogun State, \\ Nigeria.
}

\begin{abstract}
:
Background: Obesity is a global epidemic and is on the rise. Obesity is defined as a body mass index (BMI) which is equal to or more than $30 \mathrm{~kg} / \mathrm{m}^{2}$. It is one of the modifiable risk factors of type 2 diabetes. This study was undertaken to assess the relationship between BMI, WHR, RBS and BP. Method: This cross-sectional study included 776 apparently healthy adult individuals who met the inclusion criteria. Random blood samples were collected to measure RBS using glucometers. Data on BMI, waist and hip circumference and blood pressure were collected from apparently healthy individuals. Result: The mean BMI was in the overweight range, $25.49 \pm 5.15 \mathrm{~kg} / \mathrm{m}^{2}$ and was higher in females. About two-thirds (62.8\%) of the participants had abnormally elevated WHR. RBS, SBP and DBP increased significantly with increasing BMI status ( $p=0.000, p=0.000$ and $p=0.007$ respectively) and were significantly higher with abnormally elevated WHR than in participants with normal WHR ( $p=0.000, p=0.000$ and $p=0.000$ respectively). However, overweight individuals tended to have a higher RBS than the obese. There was a significant correlation between BMI and RBS (0.083, $p=0.020)$, SBP $(0.206, p=0.000)$ and $D B P(0.152, p=0.000)$. There was a slightly stronger correlation between WHR and RBS (0.093, $p=0.009), S B P(0.273, p=0.000)$ and DBP $(0.217, p=0.000)$. Conclusion: BMI and WHR are positively correlated with RBS and blood pressure in Nigeria. The Nigerian population is therefore at risk of Obesity and its related conditions (hyperglycemia and hypertension).
\end{abstract}

Keywords: Blood pressure, Body mass index, Obesity, Random blood sugar, Waist Hip ratio.

\section{Background}

Body mass index (BMI) is a good measure of general adiposity [1]. A person can be categorized as underweight if his/her BMI is $<18.5$, as normal weight if his/her BMI is in the range of 18.5-24.9, as overweight if his/her BMI is between 25 to 29.9 and as obese if his/her BMI is $\geq 30[2]$. An elevated BMI value is an established risk factor for ischemic heart disease, stroke and many cancers [3]. The global epidemic of Obesity is fast becoming a major public health problem and is worsening. In many populations, the average BMI has been rising by some percent per decade, thereby increasing concerns about the effects of increased adiposity on [4]. The diagnosis of Obesity is usually based on BMI. However, Waist Hip ratio (WHR) is thought by some to be a more sensitive indicator of Obesity because of the inclusion of abdominal fat deposition in the Syndrome X [4]. Overweight or Obesity have been known to the medical profession for more than 2000 years [5]. Excessive body weight has become a major problem in industrialized and developed countries, where it has reached epidemic proportions [6,7]. Individuals from the so called disadvantaged communities are not exempted from the epidemic. They are also at risk of obesity and its complications [8].

A number of large studies have proved that mortality increases with obesity [9-11]. Obese individuals are prone to many cardiovascular risk factors. Type 2 diabetes mellitus (T2DM) is strongly associated with overweight and obesity $[12,13]$. Lipid metabolism is also adversely affected in obesity [7, 14]. The prevalence of these risk factors substantially increases with increasing BMI [15]. Overweight and obesity are also known to be independent risk factor for cardiovascular risk disease [14]. Increased body weight is a major risk factor for the metabolic syndrome which itself is a risk factor for coronary heart disease (CHD). Many studies have shown that individuals with metabolic syndrome are at high risk for the development of T2 DM [16-21]. Higher BMI in child hood is also associated with an increased risk for CHD later in life [22]. Impaired glucose tolerance is highly prevalent in children and adolescents with severe obesity [23]. Positive correlations between BMI and glucose levels (random and fasting), body lipids levels and blood pressure (BP) have been documented [24, 25]. 
Obesity is one of the most important modifiable risk factors in the pathogenesis of type 2 diabetes [26, 27]. The mechanism by which obesity induces insulin resistance is poorly understood. Adipocytes secrete a number of biological products (leptin, TNF-alfa, free fatty acids, resistin, and adiponectin) that modulate insulin secretion, insulin action and body weight and may contribute to insulin resistance [28]. The insulin resistant state that should enhance the regulation of calorie and fat metabolism during famine and prolonged periods of fasting can be deleterious. A positive correlation is assumed to exist between BMI and blood sugar levels. The prevalence of Diabetes Mellitus (DM) in adult Nigerian population is about 3.9\% [29]. This is similar to other evolving populations in sub-Saharan Africa but is much lower than for Saudi Arabia and United Arab Emirates [29]. Population based preventive measures for the control of the DM epidemic must therefore include avoidance of adiposity through physical activity and regulated caloric intake [30, 31]. A positive correlation is thought to exist between random blood glucose and obesity. However, racial factors seem to be important in the relationship between body mass index and glucose intolerance because large studies such as the Scottish study did not demonstrate a correlation between casual blood sugar and BMI [32]. There are no previous studies in this region that sought to define the relationships between these variables. This study was undertaken to determine the correlation between random blood sugar (RBS), BMI and BP in a healthy adult Nigerian population.

\section{Materials And Methods}

A cross sectional study carried out in a semi-urban Local government Area (LGA) in Nigeria. Sagamu LGA is one of the 20 LGAs in Ogun state, Nigeria. The natives constitute part of the Remo ethnic division of Ogun state. It has an estimated population of about 269,890_and occupies an area of 640 square kilometers with an average density of 421 persons per square kilometer. The local Government has 15 political/administrative wards, 11 of which are located within the Sagamu metropolis. It is a major transit region between the southwest, southeast south- south and northern parts of Nigeria.

This household survey employed the multistage sampling technique to recruit 800 apparently healthy adults aged 18 years and above. Eight of the 15 wards were selected using simple random sampling by balloting. House numbering was done in each of the eight wards and 100 houses each were selected by stratified random sampling method. One eligible participant was recruited per house by simple random method via balloting. Data collection was done with a pretested and corrected questionnaire; Anthropometric, Laboratory and physiologic measurements were also done by duly trained final year medical students.

The questions included Age and sex while the anthropometric measurements included the height, Weight, Waist and Hip circumference.

Height was measured with stadiometer with the participants standing on and horizontal plane, heels together and stretching upwards to fullest with their hands loosely hanging down. Weight was measured with a properly calibrated portable weighting scale with participants standing erect, barefooted and wearing minimal clothes. The BMI was calculated. The individuals were classified on the basis of their BMI into Underweight $(\mathrm{BMI}<18.5)$, Normal (BMI of 18.5 to $<25)$, overweight (BMI of 25 to $<30$ ) and Obese $(\mathrm{BMI} \geq 30)$.

The Waist circumference was measured as the abdominal girth at the midpoint between the costal margins and the anterior-superior iliac spine. The Hip circumference was measured at the level of the greater trochanters. Patients were classified as normal or abnormal based on the Waist Hip ratio (WHR). WHR $>0.95$ for males and $>0.8$ for females were considered to be abnormal. Males with WHR $\leq 0.95$ and females with WHR $\leq 0.8$ were considered to be normal.

Blood pressure was measured with aneroid sphygmomanometer as described by Rose et al [33]. Individuals were classified using the JNC7 report on the prevention, detection, evaluation and treatment of High Blood Pressure into Normal (<120/80mmHg), Pre-hypertensive (120-139/80-89mmHg) and Hypertensive $(\geq$ 140/90mmHg) [34].

Random capillary blood samples were collected to measure RBS using Glucometers. Random capillary blood sugar level of $140 \mathrm{mg} / \mathrm{dl}(7.7 \mathrm{mmol} / \mathrm{l})$ was used as cut off. This value gives the highest sensitivity and specificity for diagnosis of DM using the two hour postprandial plasma glucose of $200 \mathrm{mg} / \mathrm{dl}$ or more $(\geq 11.1$ $\mathrm{mmol} / \mathrm{l})$ criterion [35].

The Data were entered into a computer and Statistical analysis was done using the SPSS 16.0 and WHO Anthro. Continuous variables were reported ad Means \pm Standard deviation. Prevalence rates were expressed as percentages. Associations were tested using the student t-test, one way ANOVA and chi square test. The extent of association was measured using the Pearson correlation coefficient. Alpha level was set at 0.05 . 
Results

\section{Results And Discussion}

Seven hundred and seven six well filled data set were available at the end of the study.

A total of 776 individuals, 200 (25.8\%) males and 576 (74.2\%) females were examined. The mean age of the participants was $42.61 \pm 14.33$ years. Among them, $232(29.9 \%)$ were overweight and $136(17.5 \%)$ were obese while, $28(3.6 \%)$ were underweight. The mean BMI was $25.49 \pm 5.15 \mathrm{Kg} / \mathrm{m}^{2}$. The mean WHR was $0.87 \pm 0.08$. Among the participants $487(62.8 \%)$ had abnormally high WHR $(>0.95$ in males and $>0.80$ in females). Mean RBS was $98.22 \pm 17.92 \mathrm{mg} / \mathrm{dl}$ (Table-1).

Comparison of these parameters between males and females showed that BMI was significantly higher in females, whereas men had significantly higher WHR as expected. However, while men tended to have WHR within what is normally expected for their sex, women were shown to have abnormally high WHR than expected for their sex (Table-2).

Diastolic and Systolic blood pressures increased significantly with increasing BMI status and were significantly higher with abnormally elevated WHR than in participants with normal WHR. RBS was also significantly higher in those with elevated WHR than in those with normal WHR. RBS tended to increase significantly with increase in BMI status but overweight individuals tended to have a higher RBS than the obese (Tables -3 and 4).

Bivariate correlation analysis showed that SBP, DBP, RBS and WHR had positive correlation with BMI. They also had a positive correlation with WHR. The variables also showed a positive correlation among themselves except that the blood pressure (systolic and diastolic) was not correlated with RBS (Table 5).

After controlling for effects of age and sex the correlation of RBS, SBP and DBP with WHR decreased to $0.078(p=0.029), 0.184(p=0.000)$ and $0.166(p=0.000)$ respectively. The correlation of SBP and DBP with BMI also decreased to $0.178(p=0.000)$ and $0.123(p=0.000)$ respectively whereas the correlation between RBS and BMI slightly increased to $0.084(p=0.000)$. RBS still had no correlation with SBP $(-0016, p=0.649)$ and $\operatorname{DBP}(0.009, p=0.806)$.

\section{Discussion}

There is a significant difference in the proportion of males and females that participated in the study. The males were often unavailable because they went out to make income for the sustenance of the family.

Overweight and obesity are some of the factors implicated in disease conditions including diabetes mellitus, and hypertension. Majority of the notable investigations about them have been carried out among western populations [7, 9-11, 14]. A few have also been done in Asian populations [36-38].

The frequency and severity of the related disease conditions are thought to increase with the increase BMI and or WHR (above normal). Our study demonstrated statistically significant differences between BMI groups (underweight, normal, overweight, Obese) and WHR groups (normal and abnormally elevated) for all the parameters that were tested (RBS, SBP and DBP). The overweight, obese and those with elevated WHR had higher values. These findings corroborate other studies, which showed that overweight and obesity are consistent parameters associated with cardiovascular risk in most populations [39-42].

The mean BMI found in our study was in the overweight range and is higher in females. This is similar to findings of another study in Nigeria [43]. High average BMI was also demonstrated in many studies in Asian [44-48]. Close to two-thirds of our study participants had abnormally elevated WHR.

In a country where majority of the population lives below poverty line and lacks proper nutrition food, the finding of an average BMI that is in the overweight and a majority with WHR values above normal values is surprising. The finding suggests that there are other factors other than food that are associated with being overweight and having abnormal fat deposition. There could be a possible interplay of genetic factors, sedentary lifestyle and lack of exercise.

Our study revealed that mean SBP, DBP, and RBS level showed a positive correlation with BMI and WHR. These findings are similar to majority of other findings in western populations $[49,50]$ and several Asian populations [25, 47, 48]. A few studies have however shown varied results. While a study in Zaria, Nigeria showed a positive correlation of BMI with RBS among males but no correlation among females [43], Bakari and his colleagues showed positive correlation of BMI with RBS in females but no correlation in males [43].

Our study showed that the correlation of mean SBP, DBP and RBS with WHR is consistently stronger than with BMI though both seem to be on the weak side. There are better ways of measuring obesity and body fat. Computed tomography (CT) scan and (Magnetic resonance imaging) MRI are the gold standard methods used to evaluate body fat distribution [51], but the WHR is a better and hence more commonly used to predict visceral fat accumulation in epidemiological studies [52, 53].

The correlation of BMI and WHR with RBS and Blood pressure were generally weakened after controlling for age and gender although they were still significant. Faheem et al had similar findings [36] while 
Turcato et al showed that in both men and women, BMI-cardiovascular risk factors correlation was no longer significant after age adjustment [25].

\section{Conclusion}

BMI and WHR are positively correlated with RBS and blood pressure in Nigeria. The Nigerian population is therefore at risk of Obesity and its related conditions (hyperglycemia and hypertension) like many western and Asian countries.

BMI or preferably WHR should be routinely checked in clinical practice and epidemiological surveys. There is a need for promotion of a healthy life style, regular exercise and proper nutrition.

\section{Limitation Of The Study}

The fasting blood sugar is the ideal measure of blood sugar level. However, its measurement was not quite feasible in this household based study. Hence (capillary) random blood sugar was used as an indicator of the blood sugar level. It is the most convenient of reaching large number of apparently healthy people.

\section{Conflict Of Interests}

The authors declare that there is no conflict of interests regarding the publication of this article.

\section{References}

[1]. Hu F. Obesity epidemiology. Oxford: Oxford university press, 2008;87-97

[2]. World Health Organization Obesity: Preventing and Managing the Global Epidemic. World Health Organization Geneva, Switzerland,1997;786-987

[3]. Prospective Studies Collaboration, Whitlock G, Lewington S, Sherliker P, Clarke R, Emberson J, Halsey J, Qizilbash N, Collins R, Peto R. Body-mass index and cause-specific mortality in 900000 adults: collaborative analyses of 57 prospective studies. The Lancet 2009; 373(9669): 1083-96.

[4]. WHO Global InfoBase team. Surveillance of chronic diseases and risk factors: Country level data and comparable estimates. Geneva: World Health Organization, 2005.

[5]. Bray GA. Historical frame work for the development of ideas about obesity. In: Handbook of obesity, Bray, GA, Bouchard C, James WPT (eds). New York: Marcel Dekker, Inc.; 1997.

[6]. World Health Organization. Food and health in Europe: a new basis for action. WHO; regional publication European series, No. 96. Copenhagen. WHO; 2004.

[7]. Grundy SM, Banett JP. Metabolic and health complications of obesity. Dis Mon 1990; 36:641-731.

[8]. Haslam DW, James WP. Obesity. Lancet 2005; 366:1197-209.

[9]. Freedman DM, Ron E, Ballard-Barbash R, Doody MM, Linet MS. Body mass index and all-cause mortality in a nationwide US cohort. Int J Obes (Lond) 2006;30:822-9.

[10]. Price GM, Uauy R, Breeze E, Bulpitt CJ, Fletcher AE. Weight, shape and mortality risk in older persons: elevated waist hip ratio, not high body mass index, is associated with greater risk of death. Am J Clin Nutr 2006;84:449-60.

[11]. Pischon T, Boeing H, Hoffmann K, Bergmann M, Schulze MB, Overvad K, et al. General and abdominal adiposity and risk of death in Europe. N Engl J Med 2008;359:2105-20.

[12]. Golditz GA, Willet WC, Rotnitzky A, Manson JE. Weight gain as a risk factor for clinical diabetes mellitus in women. Ann Intern Med 1995;122:481-6.

[13]. Chan JM, Rimm EB, Colditz GA, Stampfer MJ, Willett WC. Obesity, fat distribution, and weight gain as risk factor for clinical diabetes in men. Diabetes care 1994;17:961-9.

[14]. Hubert HB, Feinleib M, McNamara PM, Castelli WP. Obesity as an independent risk factor for cardiovascular disease; a 26 years follow-up for participants in the Framingham Heart Study. Circulation 1983;67:968-77.

[15]. Nguyen NT, Magno CP, Lane KT, Hinojora MW, Lane JS. Association of hypertension, diabetes, dyslipidemia, and metabolic syndrome with obesity: findings from the national health and nutrition examination survey, 1999 to 2004. J Am Coll Surg 2008;207:928-34.

[16]. Hanson RL, Imperatore G, Bennett PH, Knowler WC. Components of the "metabolic syndrome" and incidence of type 2 diabetes. Diabetes 2002;51:3120-7.

[17]. Resmick HE, Jones K, Rutolo G, Jain AK, Handerson J, Lu W, et al. Insulin resistance, the metabolic syndrome, and risk of incident cardiovascular disease in non-diabetic American Indians. The Strong Heart Study. Diabetes Care 2003;26:861-7.

[18]. Klein Be, Klein R, Lee KE. Components of metabolic syndrome and risk of cardiovascular disease and diabetes in beaver dam. Diabetes Care 2002;25:1790-4.

[19]. Sattar N, Gaw A, Scherbakova O, Ford I, O'Reilly DS, Haffuer SM, et al. Metabolic syndrome with and without C-reactive protein as a predictor of coronary heart disease and diabetes in the west of Scot land. Coronary Prevention Study. Circulation 2003;108:414-9.

[20]. Sattar N, Mc connachie A, Shaper AG, Blauw GJ, Buckley BM, De Crean AJ, et al. Can metabolic syndrome usefully predict cardiovascular disease and diabetes? Outcome data from two prospective studies. Lancet 2008;371:1927-35.

[21]. Eckel RH, Grundy SM, Zimmet PZ. The metabolic syndrome. Lancet 2005;365;1415-28.

[22]. Baker JL, Olsen LW, Sorvusen T. Childhood body mass index and the risk of coronary heart disease in adulthood. N Eng J Med 2007;357:2329-37.

[23]. Sinha R, Fisch G, Teague B, Tamborlane WV, Banyas B, Allen K, et al. Prevalence of impaired glucose tolerance among children and adolescents with marked obesity. N Eng J Med 2002;346:802-10.

[24]. Pucarin-cvetkovil J, Mustajbegovic J, Jelinic JD, Senta A, Nola IA, Ivankovic D, et al. Body mass index and nutrition as determinants of health and disease in population of Croatian Adriatic islands. Croat Med J 2006;47:619-26.

[25]. Turcato E, Bosello O, Di Francesco V, Harris TB, Zoico E, Bissow L, et al. Waist circumference and abdominal sagittal diameter as surrogates of body fat distribution in the elderly ; their relation with cardiovascular risk factors. Int J Obes Relat Metab Disord 2000;24:1005-10. 
[26]. World Health Organization Expert committee: Physical status; the use and interpretation of anthropometry. Report of a WHO expert committee. Technical report series 854, WHO Geneva, 1995.

[27]. Bakari AG and Onyemelukwe GC. Aetiopathogenesis of type-2 diabetes mellitus. Diabetes International 2005; 13:7-9.

[28]. Steppan CM, Bailey ST, Bhat S, Brown EJ, Banerjee RR, Wright CM, Patel HR, Ahima RS, Lazar MA. The hormone resistin links obesity to diabetes. Nature 2001; 409(6818):307-12.

[29]. International Diabetes Federation. A Prevalence estimate of diabetes mellitus, 2010 by Country Percent of adult population with diabetes, ranked highest to lowest \%. Available at http://www.allcountries.org/ranks/diabetes_prevalence_country_ranks.html. Accessed on $16^{\text {th }}$ Aug, 2103.

[30]. Khan LK, So bush K, Keener D, Goodman K, Lowry A, Kakietek J, Zaro S. Recommended Community Strategies and Measurements to Prevent Obesity in the United States. MMWR. Recommendations and Reports July 24, 2009 / 58(RR07);1-26

[31]. Das S. Introduction, low body weight type2 Diabetes Mellitus Patients. Technical series of Indian College of Physicians 2005.

[32]. Janghorbani M, Hedley AJ, Jones RB et al. Is the association between glucose level and "all causes" and cardiovascular mortality risk dependent on Body Mass index? Med J IR I 1991; 6:205-212.

[33]. Rose G. Standardization of observers in blood pressure measurement. Lancet. 1965;1:673-674.

[34]. The Seventh Report of the Joint National Committee on Prevention, Detection, Evaluation, and Treatment of High Blood Pressure (JNC 7). 2004

[35]. Somannavar S, Ganesan A, Deepa M, Datta M, Mohan V. Random Capillary Blood Glucose cut points for Diabetes and Prediabetes derived from community based opportunistic screening in India. Diabetes Care. 2009;32(4)641-3.

[36]. Faheem M, Qureshi S, Ali J, Hameed, Zahoor, Abbas F, Gul AM, Hafizullah M. Does BMI affect cholesterol, sugar, and blood pressure in general population? J Ayub Med Coll Abbottabad 2010;22(4).

[37]. Dudekula AB, Naik JL, Reddy KSN. Correlation between blood sugars and BMI with blood pressure among type 2 diabetic adults. Asian J. Exp. Biol. Sci. 2012; 3(2):378-383.

[38]. Vittal BG, Praveen G, Deepak P. A Study of body mass index in healthy individuals and its relationship with fasting blood sugar. Journal of Clinical and Diagnostic Research. 2010 December; 4:3421-3424.

[39]. Panagiotakos DB, Pitsavos C, Chrysohoou C, Risvas G, Kontogianni MD, Zampelas A, et al. Epidemiology of overweight and obesity in a Greek adult population: the ATTICA Study. Obes Res 2004;12:1914-20.

[40]. Brown CD, Higgins M, Donato Ka, Rohde FC, Garrison R, Obarzanek E, et al. Body mass index and prevalence of hypertension and dyslipidemia. Obes Res 2000;8:605-19.

[41]. McGee Dl. Diverse Population Collaboration. Body mass index and mortality; a meta-analysis based on person-level data from twenty-six observational studies. Ann Epidemiol 2005;15:87-97.

[42]. Kragelund C, Hassager C, Hildebrandt P, Torp-Pedersen C, Kober L. Impact of obesity on long-term prognosis following acute myocardial infarction. Int J Cardiol 2005;98:123-31.

[43]. Bakari AG, Onygemelukwe GC, Sani BG, Aliyu IS, Hassan SS, Aliyu TM. Relationship between random blood sugar and body mass index in an African population. Int J Diabetes Metab 2006;14:144-5.

[44]. Sendhu HS, Koley S, Sandhu KS. A study of correlation between lipid profile and BMI in patients with diabetes mellitus. J Human Ecol 2008;24:227-9.

[45]. Hussain S, Hussain I, Sana B, Waheed K, Qaisera S. Association of type 2 diabetes mellitus with biometric variable: A study in Sir Ganga Ram Hospital, Lahore. Ann King Edward Med Uni 2009;15(2):48-53.

[46]. Azizi F, Rahmani M, Emami H, Mimian P, HajiPur R, Madjid M, et al. Cardiovascular risk factors in an Iranian urban population: Tehran Lipid and glucose study (Phase-I). Soz Praventivmed. 2002;47:408-26.

[47]. Costa GB, Horta N, Resende ZF, Souza G, Barreto LM, Correia LH, et al. Body mass index has a good correlation with protherosclerotic profile in children and adolescents. Arq Bras Cardiol. 2009;93:261-7.

[48]. Aghasadeghi K, Zarei-Nezhad M, Keshavarzi A, Mehravani D. The prevalence of coronary risk factors in Iranian lor migrating tribe. Arch Iran Med 2008;11:322-5.

[49]. Lee KS, Cho SD, Hong HS. The risk factors associated with increase blood pressure sugar and lipids in multiphasic health checkup examinee. Korean J Prev Med 2000;33:69-75.

[50]. Lindsay RS, Hanson RL, Roumain S, Ravussin E, Knowler WC, Tataranni A. Body mass index as a measure of adiposity in children and adolescent: Relationship to adiposity by dual energy-ray absorptiometry and to cardiovascular risk factors. J Clinical Endocrinol Metab 2001;86:4061-7.

[51]. Van der Kooy K, Seideel JC. Techniques for the measurement of visceral fat: a practical guide Int J Obes Relat Metab Disord 1993;17:187-96.

[52]. Lemieux S, Prudhomme D, Bouchard C, Trembley A, Despres JP. A single threshold value of waist girth identifies normal weight subjects with excess visceral adipose tissue. Am J Clin Nutr 1996;64:685-93.

[53]. Despres JP, Prudhomme D, Pouliot MC, Trembley A, Bouchard C. Estimation of deep abdominal adipose tissue accumulation from simple anthropometric measurement in men. Am J Clin Nutr 1991;54:471-7.

Table 1: Frequency distribution of Respondents' parameters

\begin{tabular}{lll}
\hline Parameters & Frequency & Percentage \\
\hline Age (in years) & & \\
Less than 25 & 73 & 9.4 \\
$25-34$ & 167 & 21.5 \\
$35-44$ & 204 & 26.3 \\
$45-54$ & 164 & 21.2 \\
$55-64$ & 104 & 13.4 \\
$\geq 65$ & 64 & 8.2 \\
Sex & & \\
Male & 200 & 25.8 \\
Female & 576 & 74.2 \\
BMI Classification & & \\
Underweight & 28 & 3.6 \\
Normal weight & 380 & 49.0 \\
Overweight & 232 & 29.9 \\
Obese & 136 & 17.5 \\
Waist-Hip ratio & &
\end{tabular}




Normal
Abnormal (elevated)
Blood pressure classification
Normal
Pre-hypertension
Hypertension
Random blood sugar
Normal
Hyperglycemia
Hypoglycemia

$\begin{array}{ll}289 & 37.2 \\ 487 & 62.8 \\ & \\ 234 & 30.2 \\ 273 & 35.2 \\ 269 & 34.7 \\ & \\ 708 & 91.2 \\ 56 & 7.2 \\ 12 & 1.5\end{array}$

Table 2: Sex distribution of mean values of risk factors

\begin{tabular}{llll}
\hline Parameters & Male $(\mathbf{n}=\mathbf{2 0 0})$ & Female $(\mathbf{n}=\mathbf{5 7 6})$ & P value \\
\hline BMI & $23.26 \pm 3.33$ & $26.26 \pm 5.45$ & 0.000 \\
WHR & $0.90 \pm 0.08$ & $0.86 \pm 0.07$ & 0.000 \\
RBS & $98.88 \pm 18.92$ & $97.99 \pm 17.57$ & 0.544 \\
Systolic BP & $135.30 \pm 23.19$ & $132.63 \pm 25.65$ & 0.194 \\
Diastolic BP & $79.94 \pm 15.65$ & $80.13 \pm 16.13$ & 0.884 \\
\hline
\end{tabular}

Independent sample $t$-test used for comparing means

Table 3: Distribution of mean values risk factors according to BMI groups

\begin{tabular}{|c|c|c|c|c|c|}
\hline \multirow[b]{2}{*}{ Parameters } & \multicolumn{4}{|l|}{ BMI Groups } & \multirow[b]{2}{*}{ P value } \\
\hline & $\begin{array}{l}\text { Underweight } \\
(\mathrm{n}=28)\end{array}$ & $\begin{array}{l}\begin{array}{l}\text { Normal } \\
(\mathbf{n}=380)\end{array} \\
\end{array}$ & $\begin{array}{l}\begin{array}{l}\text { Overweight } \\
(\mathbf{n}=232)\end{array} \\
\end{array}$ & Obese $(n=136)$ & \\
\hline RBS & $91.86 \pm 14.02$ & $96.81 \pm 16.17$ & $101.14 \pm 20.64$ & $98.47 \pm 17.67$ & 0.000 \\
\hline Systolic BP & $115.57 \pm 20.37$ & $129.51 \pm 22.60$ & $137.95 \pm 24.21$ & $139.71 \pm 30.02$ & 0.000 \\
\hline Diastolic BP & $68.57 \pm 12.83$ & $78.87 \pm 16.06$ & $81.53 \pm 14.68$ & $83.35 \pm 17.22$ & 0.007 \\
\hline
\end{tabular}

Differences between BMI groups compared using one way ANOVA

Table 4: Distribution of mean values risk factors according to WHR groups

\begin{tabular}{llll}
\hline & \multicolumn{2}{l}{ WHR Groups } & \\
\cline { 2 - 3 } Parameters & Abnormal/elevated $(\mathbf{n}=\mathbf{4 8 7})$ & Normal $(\mathbf{n = 2 8 9})$ & P value \\
\hline RBS & $101.02 \pm 19.46$ & $95.18 \pm 14.49$ & 0.000 \\
\hline Systolic BP & $137.07 \pm 26.74$ & $126.99 \pm 20.46$ & 0.000 \\
\hline Diastolic BP & $82.19 \pm 16.75$ & $76.53 \pm 13.95$ & 0.000 \\
\hline
\end{tabular}

Differences between WHR groups compared using one way ANOVA

Table 5: Correlation between BMI, RBS and BP \{correlation coefficient (p-value)\}

\begin{tabular}{llllll}
\hline & BMI & WHR & RBS & Systolic BP & Diastolic BP \\
\hline BMI & 1 & & & & \\
\hline WHR & $0.148(0.000)$ & 1 & & & \\
\hline RBS & $0.083(0.020)$ & $0.093(0.009)$ & 1 & & \\
\hline Systolic BP & $0.206(0.000)$ & $0.273(0.000)$ & $0.012(0.737)$ & 1 & \\
\hline Diastolic BP & $0.157(0.000)$ & $0.217(0.000)$ & $0.025(0.483)$ & $0.750(0.000)$ & 1 \\
\hline
\end{tabular}

